\title{
The Effect of Skin Traction on Preoperative Pain and Need for Analgesics in Patients With Intertrochanteric Fractures: A Randomized Clinical Trial
}

\author{
Alireza Manafi Rasi ${ }^{1}$; Farzad Amoozadeh ${ }^{1}$; Salim Khani ${ }^{1,{ }^{*}}$; Amin Kamrani Rad ${ }^{1}$; Ali Sazegar ${ }^{1}$ \\ ${ }^{1}$ Orthopedics Surgery Department, Shahid Beheshti University of Medical Sciences, Tehran, IR Iran \\ ${ }^{*}$ Corresponding author: Salim Khani, Orthopedics Surgery Department, Shahid Beheshti University of Medical Sciences, Tehran, IR Iran. Tel: +98-9188328557, Fax: +98-2177569991, \\ E-mail: Khani_Salim@yahoo.com
}

Received: May 7, 2013; Revised: January 13, 2015; Accepted: February 28, 2015

\begin{abstract}
Background: Preoperative skin traction is applied for many patients with hip fracture. However, the efficacy of this modality in pain relief is controversial.

Objectives: The aim of the current study was to investigate the effects of skin traction on pain in patients with intertrochanteric fractures. Patients and Methods: A total of 40 patients contributed in this randomized clinical trial. Patients were randomly allocated into two equal groups: the skin traction ( $3 \mathrm{~kg}$ ) and control groups. The severity of pain was recorded at admission and 30 minutes, one, six, 12, and 24 hours after skin traction application utilizing a Visual Analogue Scale (VAS). In addition, the number of requests for analgesics was recorded. Finally, the mean severity of pain in each measurement and the mean number of analgesic requests were compared between the two groups.

Results: The severity of pain was significantly decreased in skin traction group only at the end of the first day after traction application (2.7 \pm 0.8 vs. $3.3 \pm 0.9 ; \mathrm{P}=0.042$ ), while there was no significant difference between the two groups in other pain measurements. The number of requests for analgesics was the same between the two groups.

Conclusions: Although skin traction had no effect on analgesic consumption, it significantly decreased the pain at the end of the first day. The application of skin traction in patients with intertrochanteric fractures is recommended.
\end{abstract}

Keywords: Intertrochanteric Fractures; Skin; Traction; Pain; Visual Analog Scale; Analgesics

\section{Background}

Hip fracture is one the most important and controversial orthopedic problems in the elderly, which causes high morbidity and mortality (1-3). The one-year mortality rate reported following this fracture ranges from $11 \%$ to $34 \%$ (4-6) and this rate increases with age (7, 8). It is demonstrated that after the age 50 , the possibility of hip fracture doubles every ten years $(9,10)$. Moreover, various studies conducted in different countries such as the United States, Canada, European Countries, Australia, and Japan have demonstrated that the prevalence of this fracture is increasing (11-13). In an estimate submitted by Royal College, 117000 individuals will develop hip fractures in 2016 (14). In addition, it is estimated that 2.6 million and 4.5 million people will develop these fractures in 2025 and 2050, respectively (15). In some studies, these figures have been reported to be 7.3 to 21.3 million people in 2015 (16). The therapeutic costs of these damages are estimated to be 10 billion dollars annually (17). This trend in the prevalence of these fractures along with the increase in the average age of the society and life expectancy demonstrate that hip fractures is the challenges to the health systems, both currently and in the future, which can assume economic, social, and mental burden on individuals and society $(1,10,18-21)$. One of the first measures that has been taken in the health centers of the world as well as in Iran for the patients that suffer from hip fractures is employing skin traction and it is believed that good results such as pain alleviation can be achieved by tensions through this method $(22,23)$. Hip fracture is accompanied by severe pain and looking for methods for alleviating pain in these patients prior to operation is highly desirable. This matter is especially important in young patients because despite hip fracture is very rare among the youth, as it results from traumas with high energy, it is accompanied by more severe pain (24). Studies have been conducted on the role of skin traction in the pain of these patients (23-28), but the present results are vague as well as contradictory and require more randomized studies. In addition, regardless of all related studies, this method is being used in trauma centers.

\section{Objectives}

Based on this and to further clarification of the subject,

Copyright (C) 2015, Kashan University of Medical Sciences. This is an open-access article distributed under the terms of the Creative Commons Attribution-NonCommercial 4.0 International License (http://creativecommons.org/licenses/by-nc/4.0/) which permits copy and redistribute the material just in noncommercial usages, provided the original work is properly cited. 
and through a randomized clinical trial, we decided to investigate the effect of using the skin traction on the severity of pain and the dose of the narcotic medicines in patients with intertrochanteric fracture.

\section{Patients and Methods}

In this randomized clinical trial, 40 patients with intertrochanteric fracture, aged 60 to 85 years old, were recruited. Prior to the study, the patients or their companions were asked to fill in and sign the inform consent form in case of the willingness to participate in the study. In addition, they were ensured that in case of the severe pain, all possible measures would be taken for pain relief. All patients addicted to smoking or using opioids and also patients who were not able express their pain degree were excluded from the study. In addition, patients with various traumas and patients who were not able to express their pain or abstained from signing the consent form were excluded. Patients were randomly allocated into two equal groups. In one group, skin traction was applied to the fractured limb using a 3-kg weight while in the other group skin traction was not applied.

Demographic and background data of patients such as age, sex, mechanism of damage, and type of fracture were recorded in special data sheets. Visual Analogue Scale (VAS) was used to measure pain, which is a measurement instrument consisting of a $10-\mathrm{cm}$ line in which zero indicates no pain and ten indicates the worse pain imaginable. The severity of pain in patients was recorded at admission and 30 minutes, one, six, 12, and 24 hours after skin traction by VAS. Moreover, during this period, the number of requests for analgesics was recorded. In case the patients requested analgesics for pain alleviation, $3 \mathrm{mg}$ of morphine would be administered intravenously. In the end, the obtained data were analyzed using independent-samples ttest and $\chi^{2}$ test by SPSS 16 (SPSS Inc, Chicago, Illinois, USA). In this study, P value $<0.05$ was considered as a significant level.

\section{Results}

The background data of the participants in the study are presented in Table 1, which shows that there was no significant difference between the patients of the two groups in terms of age, sex, and mechanism of the damage. Table 2 represents the mean of patients' pain in six measurement points. There was no statistically significant difference in the mean of the pain scores between two groups. The mean of pain scores of the second measurement (one hour after skin traction) in skin traction group was somewhat more than the other group; however, this difference was not significant. There was no differentiation in the mean pain intensity between two groups at six and 12 hours, but it was slightly lower in the skin traction group. The mean of pain severity score at 24 hours of traction application was remarkably higher in the skin traction group compared with the other group $(\mathrm{P}=0.0$ 42). Moreover, the t-test indicated that the severity of pain has been decreased significantly $(P=0.0001)$ at the end of the first day compared to the time of admission. The mean frequency of requests for analgesics was $1.65+0.7$ in the group of skin traction, and $1.6+0.6$ in the control group. The Mann-Whitney $U$ test indicated that there could be no significant difference between the two groups.

\begin{tabular}{|c|c|c|c|}
\hline Group & Skin Traction $(n=20)$ & No Skin Traction $(n=20)$ & P Value \\
\hline Age, $y$ & $69.5 \pm 8.2$ & $67.8 \pm 6.6$ & 0.524 \\
\hline Gender & & & 0.288 \\
\hline Male & 4 & 7 & \\
\hline Female & 16 & 13 & \\
\hline Mechanism of fracture & & & 0.429 \\
\hline Falling & 15 & 17 & \\
\hline Accident & 3 & 5 & \\
\hline
\end{tabular}

${ }^{\mathrm{a}}$ Data are presented as mean \pm standard deviation or frequency.

\begin{tabular}{|c|c|c|c|c|c|}
\hline \multirow[t]{2}{*}{ Times of Measurement } & \multicolumn{2}{|c|}{ Skin Traction } & \multicolumn{2}{|c|}{ No Skin Traction } & \multirow[t]{2}{*}{ PValue } \\
\hline & Mean \pm SD & Range & Mean \pm SD & Range & \\
\hline 30 minutes & $6.3 \pm 1.3$ & $5-8$ & $6.4 \pm 1.1$ & $4-9$ & 0.895 \\
\hline 1st hour & $6.2 \pm 1.2$ & $4-8$ & $5.7 \pm 0.9$ & $4-8$ & 0.139 \\
\hline 6th hour & $5.3 \pm 1$ & $5-8$ & $5.3 \pm 1$ & $4-9$ & 0.291 \\
\hline 12th hour & $4.1 \pm 0.8$ & $3-6$ & $4.6 \pm 1$ & $3-6$ & 0.086 \\
\hline 24th hour & $2.7 \pm 0.8$ & $2-5$ & $3.3 \pm 0.9$ & $2-5$ & 0.042 \\
\hline
\end{tabular}




\section{Discussion}

The most important finding of the current research was that the application of skin traction assists decreasing the pain severity (prior to the surgery in the patients with intertrochanteric fracture), but the application of skin traction has no effect on the needs for analgesics such as intravenous morphine.

Hip fractures in young patients require urgent surgical intervention. However, complex medical situations related to high-energy trauma in most of these subjects may cause a delay in the time to appropriate intervention. Therefore, pain control is of critical importance in preoperative patients $(14,15)$. Skin traction is one of the treatment enterprises, which are applied to the patients with intertrochanteric fracture in numerous hospitals. Despite the frequent usage of this method and different studies regarding the effect of skin (or skeleton) traction on the pain of these patients, there is still disagreement with this type of traction. In addition, there has been no adequate proof for its effectiveness or ineffectiveness. Accordingly, we decided to indirectly (by the means of both groups owning the same characteristics) investigate the effect of skin traction on the pain of the patients with intertrochanteric fracture. In 2002, Yip et al. (23) investigated the effect of skin traction on 311 patients with proximal femur fracture in an indirect and predictive study. They witnessed that skin traction decreased pain, but the amount of needs of analgesic in both groups (without equal traction) was similar. They concluded that there could be no derivation from skin traction activities; then, its routine application should be stopped (23). Moreover, Estrada-Masllorens et al. (25) compared the pain of the patients with intertrochanteric fracture with and without skin traction. In their study, the pain of the patients (until 48 hours after admission to the hospital) was measured and then the researchers realized that skin traction has no effect on decreasing the patients pain (25). Both studies, which have been published in 2001 and 2011, indicated that the traction (both skin and skeleton) before the surgery has no effect on the pain of patients with hip fracture. Not only these researchers noted that the existed proofs are not sufficient to reject the application of traction, but also they support more precise study in this case $(26,27)$. Saygi et al. investigated the effect of skin traction on pain and the usage of analgesics on the patients with intertrochanteric fracture. They concluded the similar results (24). In another study, skin traction kit without weight was applied (placebo group) in addition to traction and pillow methods. Better pain control was achieved in the placebo group than in the other two groups. This significant difference was due to two factors. First, the skin traction kit without weight allowed semiflexion and external rotation and thus, reduced pain due to the lack of traction. Second, the skin traction kit without weight is believed to have created a placebo effect as it revealed more successful results in providing statisti- cally significant reduction in pain compared to the group in which only pillow application was used. On the other hand, as indicated by previous studies, skin traction with weight is not a benign treatment (21-23). As above and in many studies in this field, the ineffectiveness of skin traction has been shown. In contrast, in our research, the application of skin traction resulted in a noticeable decrease of pain intensity 24 hours after admission compared to the group without skin traction. In the current study, both groups had shown decrease in pain intensity after a while, but the patients applying skin traction showed more comfort compared with the ones without traction. Consequently, Skin traction plays an important role on the patients' relief and relaxation.

Another finding of the current research illustrates that skin traction shows no effect on the needs of analgesics. Accordingly, it is noted that skin traction is not capable of interfering with the amount of the administrated intravenous morphine in the patients with intertrochanteric fracture (mostly elderly showing acceptable decrease of analgesics).

Similar to the other studies, the current study had some limitations. The most important limitation of the current study was the low numbers of patients. In the next study, more patients should be attended. In addition, there could be some other studies contrasting the effect of both skin and bone traction (28-30), while we have not measured the bone traction. We recommend taking this matter into account by the researchers.

In conclusion, although the application of skin traction has no interference with the need for analgesics (as it remarkably decreases the pain of the patients with intertrochanteric fracture), it assists the patients comfort and relaxation. The application of skin traction before the surgery in these patients is recommended.

\section{Authors' Contributions}

Study concept and design: Alireza Manafi Rasi and Farzad Amoozadeh; Acquisition of data and Analysis: Salim Khani, Amin Kamrani Rad, and Ali Sazegar; Statistical analysis: Farzad Amoozadeh, Salim Khani; Drafting the manuscript: Alireza Manafi Rasi, Farzad Amoozadeh, Salim Khani, Amin Kamrani Rad, and Ali Sazegar.

\section{Funding/Support}

This study was supported by Shahid Beheshti University of Medical Sciences, Tehran, IR Iran.

\section{References}

1. Boufous S, Finch CF, Lord SR. Incidence of hip fracture in New South Wales: are our efforts having an effect? Med J Aust. 2004;180(12):623-6.

2. Sahin O, Demirors H, Akgun R, Senturk I, Tuncay IC. Dynamic hip screw versus proximal femoral nail for treatment of trochanteric hip fractures: an outcome analyses with a minimum 2 years of follow-up. European Journal of Orthopaedic Surgery \& Traumatology. 2011;22(6):473-80. 
3. Verbeek DO, Ponsen KJ, Goslings JC, Heetveld MJ. Effect of surgical delay on outcome in hip fracture patients: a retrospective multivariate analysis of 192 patients. Int Orthop. 2008;32(1):13-8.

4. Elliott J, Beringer T, Kee F, Marsh D, Willis C, Stevenson M. Predicting survival after treatment for fracture of the proximal femur and the effect of delays to surgery. $J$ Clin Epidemiol. 2003;56(8):788-95.

5. Lawrence VA, Hilsenbeck SG, Noveck H, Poses RM, Carson JL. Medical complications and outcomes after hip fracture repair. Arch Intern Med. 2002;162(18):2053-7.

6. Richmond J, Aharonoff GB, Zuckerman JD, Koval KJ. Mortality risk after hip fracture. J Orthop Trauma. 2003;17(1):53-6.

7. Gdalevich M, Cohen D, Yosef D, Tauber C. Morbidity and mortality after hip fracture: the impact of operative delay. Arch Orthop Trauma Surg. 2004;124(5):334-40.

8. Tanner DA, Kloseck M, Crilly RG, Chesworth B, Gilliland J. Hip fracture types in men and women change differently with age. BMC Geriatr. 2010;10:12.

9. Walter LC, Lui LY, Eng C, Covinsky KE. Risk of hip fracture in disabled community-living older adults. J Am Geriatr Soc. 2003;51(1):50-5.

10. Zuckerman JD. Hip fracture. N Engl J Med. 1996;334(23):1519-25.

11. Cumming RG, Nevitt MC, Cummings SR. Epidemiology of hip fractures. Epidemiol Rev. 1997;19(2):244-57.

12. Taheri NS, Blicblau AS, Singh M. Comparative study of two materials for dynamic hip screw during fall and gait loading: titanium alloy and stainless steel.J Orthop Sci. 2011;16(6):805-13.

13. Orimo H, Hashimoto T, Shiroki M, Hukunaga M, Fujiwara S, Nakamura T. The Epidemiology of osteoporosis in Japan. Jpn Med. 1995;370:27-30.

14. Hoffenberg R, James OFW, Brocklehurst JC, Green ID, Horrocks P, Kanis JA, et al. Fractured neck of femur: Prevention and management. Summary and recommendations of a report of the Royal College of Physicians. JRoyal Coll Physicians London. 1989;23(1):8-14.

15. Lorich DG, Geller DS, Nielson JH. Osteoporotic pertrochanteric hip fractures: management and current controversies. J Bone Joint Surg. 2004;86(2):398-410.

16. Gullberg B, Johnell O, Kanis JA. World-wide projections for hip fracture. Osteoporos Int. 1997;7(5):407-13.

17. Sattin RW. Falls among older persons: a public health perspective. Annu Rev Public Health. 1992;13:489-508.
18. Harrington P, Nihal A, Singhania AK, Howell FR. Intramedullary hip screw versus sliding hip screw for unstable intertrochanteric femoral fractures in the elderly. Injury. 2002;33(1):23-8.

19. Jette AM, Harris BA, Cleary PD, Campion EW. Functional recovery after hip fracture. Arch Phys Med Rehabil.1987;68(10):735-40.

20. de Palma L, Rizzi L, Lorini G, Greco F. Survival after trochanteric fracture. Acta Orthopaedica. 1992;63(6):645-7.

21. Fawnworth MG, Kenny P, Shiel A. The costs and effects of early discharge in the management of fractured hip. Age Ageing. 1994;23(3):190-4.

22. Anderson GH, Harper WM, Connolly CD, Badham J, Goodrich N, Gregg PJ. Preoperative skin traction for fractures of the proximal femur. A randomised prospective trial. J Bone Joint Surg Br. 1993;75(5):794-6.

23. Yip DK, Chan CF, Chiu PK, Wong JW, Kong JK. Why are we still using pre-operative skin traction for hip fractures? Int Orthop. 2002;26(6):361-4.

24. Saygi B, Ozkan K, Eceviz E, Tetik C, Sen C. Skin traction and placebo effect in the preoperative pain control of patients with collum and intertrochanteric femur fractures. Bull NYU Hosp Jt Dis. 2010;68(1):15-7.

25. Estrada-Masllorens JM, Cabrera-Jaime S. [Randomised clinical trial on pain control in intertrochanteric fractures of the femur with and without skin traction]. Enferm Clin. 2011;21(5):264-70.

26. Handoll HHG, Queally JM, Parker MJ. Pre-operative traction for hip fractures in adults. Cochrane Database Syst Rev. 2011;7(12):CD000168.

27. Parker MJ, Handoll HHG. Pre-operative traction for fractures of the proximal femur in adults. Cochrane Database Syst Rev. 2006;19(3):CD000168

28. Even JL, Richards JE, Crosby CG, Kregor PJ, Mitchell EJ, Jahangir $\mathrm{AA}$, et al. Preoperative skeletal versus cutaneous traction for femoral shaft fractures treated within 24 hours. J Orthop Trauma. 2012;26(10):e177-82.

29. Resch S, Thorngren KG. Preoperative traction for hip fracture: a randomized comparison between skin and skeletal traction in 78 patients. Acta Orthop Scand. 1998;69(3):277-9.

30. Vanlaningham CJ, Schaller TM, Wise C. Skeletal versus skin traction before definitive management of pediatric femur fractures: a comparison of patient narcotic requirements. J Pediatr Orthop. 2009;29(6):609-11. 